\title{
An approach to the notion of the reflective teacher and its application to mathematics education
}

\author{
Elisabeth Ramos-Rodríguez ${ }^{1}$, Pablo Flores Martínez ${ }^{2}$, and João P. da Ponte ${ }^{3}$
}

\begin{abstract}
Within research into the teaching profession, there are two main areas of interest, which have been thoroughly defined and consolidated: teacher's knowledge and teacher's professional development. This paper considers the latter area, and specifically sets out to define the concept of the reflective teacher and to show how we have applied this concept in our research. It aims at defining a more precise notion of teachers' professional development linked to the concept of a reflective teacher, drawing on information from different interdisciplinary sources so as to frame the concept clearly. We discuss the conditions which determine the reflective teacher, and report on how these were put to use in a training course for practising teachers in which participants reflected on challenging episodes from their professional experience. We hope that clarifying this term will enable different educational agents (school teachers, teacher trainers or researchers) to have an informed view that can be interpreted and critiqued, and that it will also be of value to initial teacher training and to in-service courses.
\end{abstract}

Key words reflective practice, mathematics education, thought, professional development, knowledge.

\section{Introduction}

A review of the perspectives from different researchers on the matter enables us to establish similarities and differences between reflecting and thinking. In this paper, we attempt to clear up the significance of the notion of reflection by answering the question is it a need or a whim? In other words, is being a reflective teacher a trend that has recently become established within the profession, or is it a feature that is becoming increasingly necessary in order for teachers to go about their work? Taking these elements into consideration, we attempt to answer what interests, what does it mean to be a reflective mathematics teacher? Analysing the views from various authors in the field, we intend to answer the question. In attempting to answer these questions, we discuss the ideas of several authors that introduce or use this notion, specifying their thoughts on the topic. We continue with contributions from recent authors on the subject. Finally, we broaden the vision of the reflective teacher from our own research into mathematics teacher education.

\section{Is reflecting the same as thinking?}

The question of whether these terms refer to the same or different notions has been debated for decades, the relation between them remaining unresolved. In this paper, we address the subject from two perspectives: the origin of the terms and the triadic configuration thought-action-reflection.

Amongst early uses of the term "reflection", we can highlight the contribution of Dewey's (1910) disquisition which explores in detail the notions attaching to the concept. Among Dewey's conceptions, a critical element defining reflective thought is that of inquiry. Dewey (1910) states that reflection "is marked by acceptance or rejection of something as reasonably probable or improbable." (ibid., 4), and it is this questioning of reality, facts and evidence which distinguishes reflection from any other type of thought. With this view, based on ideas by earlier thinkers, such as Plato, Aristotle, Confucius, Lao Tzu, Solomon and Buda, Dewey is recognized as the key author for the notion of reflection in the twentieth century (Hatton and Smith, 1995).

In his studies about thought and action, Dewey reaches the idea of reflection when differentiating three types of action: impulsive action, based on trial and error, routine action, mainly centred on authority and tradition, and reflective action, involving volition and intuition, and characterised by a search for logical and rational solutions to practical problems. Reflective action "is the active, persistent, and careful consideration of any belief or supposed form of knowledge in the light of the grounds that support it and further conclusions to which it leads" (Dewey, 1910, 9). While the first two are passive

\footnotetext{
${ }^{1}$ Pontificia Universidad Católica de Valparaíso. Address: Avenida Brasil, 2950, Valparaíso, Chile. Phone number: 056322274074. elisabeth.ramos@ucv.cl

${ }^{2}$ Universidad de Granada, Spain. Address: La Cartuja, s/n, 18011, Granada, Spain.pflores@ugr.es

${ }^{3}$ Instituto de Educação, Universidade de Lisboa, Portugal. Address: Alameda da Universidade, 1649-013 Lisbon, Portugal. jpponte@ie.ulisboa.pt
} 
modes, reflective action "involves not simply a sequence of ideas, but a consequence" (Dewey, 1910, 9), and it is for this reason that careful consideration is required, so that the response is rational, consistent with one's goals and capable of being modified.

In the field of education, teachers are encouraged to bring a reflective approach to their practice, eschewing the trial and error mode above, not least to avoid exposing their pupils to any risks in such a sensitive environment. Teachers are required to keep the goals of the teaching-learning process in mind, which means balancing reflection on practice with the need to maintain a perspective. This means recognising that teaching involves much that is non-replicable, partly because the circumstances at any given moment are unique, and partly because the participants themselves are idiosyncratic (Smyth, 1989). In terms of Dewey's analysis, the consequence of teachers' reflective action in solving problems is the learning and development accrued by their practice.

The idea of reflection connected to action proposed by Dewey is taken up and developed by Schön (1983), who defines the notion of "reflective practitioner". He lays emphasis on the practical aspects of other professions besides teaching, where the practical dimension goes beyond merely finding specific applications for theory. The reflective disposition of the practitioner highlighted by Schön is not exclusive to teachers, but it is teachers who embody this attitude in the field of education in one of his books (Schön, 19883). This focus on the teacher has been especially influential to us for exploring the notion of reflective practitioner in the field of education. Even so, we leave open the possibility of extending the concept to other professions exhibiting similar complexity in terms of reflection within their field of action, such as nursing, where the notion of reflective practice is widely employed (Goulet, Larue, and Alderson, 2015). In the case of the teaching profession, in the course of their day to day activity teachers need to respond to circumstances as they arise, drawing on acquired habits of reflective practice. Schön $(1983,1987)$ states that reflection is closely bound up with action and draws a distinction between reflective practice, which concerns understanding and improving one's practice, teaching or action (Dewey 1910; Zeichner 1993), and technical rationality, which reduces solutions to problems to the selection of technical means, only appropriate for certain purposes. Reflective action concerns unifying the teacher's practice with their need to respond to circumstances, and this requires habits of reflective practice. Despite Dewey's work in the area of reflective action, there appears to be little agreement about how to characterise reflection as a special form of thinking (Hatton and Smith 1995). Reflective action concerns the application of solutions to problems after these have been carefully considered, thus generating a complete cycle of "doing reflecting", and stands in contrast to routine action which is prompted by impulses, tradition or authority. Hence, reflective action is closely linked to a careful and persistent consideration of practice in the light of knowledge and beliefs, showing open-minded attitudes, responsibility and wholeheartedness (Hatton and Smith 1995), attitudes which Dewey (1993) also draws attention to.

Korthagen et al. (2001) acknowledge that the term reflection is used sometimes to describe a process similar to the act of thinking, and underlines the similarities between the two. Other authors draw attention to the difference between thought and reflection. For instance, for Perrenoud, reflection implies "some restraint and, therefore, a minimum distance before the action" (2002, p.30), meaning something more than the act of thinking at the moment of action. But this does not mean that reflection does not take thinking into account; rather, it emphasizes that reflection is a more complex process than an impulsive or routine action: it is a step beyond the natural act of thinking or saying something (Oliveira and Serrazina, 2002).

With the foregoing in mind, we must be careful with the notion of perception. As Zeichner warns, "We have reached an extreme in which the existing set of beliefs in the educational community about teaching, learning, education and social order, is incorporated into the discourse on reflective practice, practically emptying the term reflection of meaning" $(1993,44)$. In other words, the term can be used lightly, without the depth it requires, which is why the need to clearly define what reflecting is and what we understand by the reflective teacher (Flores, 2007), something that will be covered in the next section.

\section{Is being a reflective teacher a need or is it a trend?}

There is general recognition today that a desirable aspect of professionalism in teaching is the capacity to be reflective (Jaworski, 1993; Keazer, 2014; Korthagen, Kessels, Koster, Lagerwerf, and Wubbels, 2001; Mason and Klein, 2013). Similarly, there has been considerable interest in approaching other professions reflectively, such as medicine (Little, 2015), nursing (Goulet, Larue, and Alderson, 2015) and engineering (Finlayson, 2016). Jaworski (1993) describes several episodes of reflection by three distinct practitioners as illustrations of the importance of reflection in the process of the teachers' professional development. 
But, why should we demand that teachers be reflective? In order to study this question, we begin by examining the position of educational agents from different contexts, specifically, from Chile, Spain and from the PISA study, which highlight its current relevance. Subsequently, we examine its appropriateness in two fields: general education and mathematics education.

\section{The position of different educational agents}

Promoting the skills of reflection and critical thinking in teachers has featured highly amongst the priorities of current educational policies. In Chile, for example, the Ministry of Education is providing the necessary financial support and human resources for initial and continuing teacher training, with an emphasis on "keenly developing teachers' reflective skills and critical thinking" (Miranda, 2003). Here, the term "reflective teacher" is used in the context of professional growth and consolidation, as an instrument for achieving curricular change. Among this kind of government investment in teacher training, we can find a series of professional development strategies, which were set up in 1996. These consisted of opportunities for serving teachers to travel abroad to take specialised and graduate diploma courses to improve their teaching by developing critical thinking skills which they could apply to their work environment and by studying curricular and pedagogical innovations which they could share with their colleagues (Miranda 2003). More recently, the Community Workshop project has been another government-sponsored initiative for in-service training, again aimed at promoting reflection as a vehicle of change within schools (Madrid, 2007). We would highlight the role that reflection takes at all stages of the practice of teaching, and that it constitutes a vital element in the consideration of any teacher training reform (Fuentealba and Galáz, 2008). Being a reflective practitioner is something that the Chilean Ministry of Education, through various initiatives, actively within amongst the teaching sector.

In the specific area of mathematics education, the notion of reflection can be perceived in the PISA assessment, which seeks to examine the extent to which the OCDE countries educate reflective citizens. In fact, the notion of literacy or mathematics competence claimed by PISA implies the personal ability to identify and understand the role that mathematics plays in the world, to make properly founded judgements and to draw on mathematical knowledge when circumstances demand it, as a constructive, committed and reflective citizen (OCDE, 2003).

Spain takes this model - developing reflective citizens - and applies it in its school curricula, emphasising the teacher's formative duty to promote reflective thinking skills among their students. We wonder whether the teacher can foster this type of thinking among their students if they do not practice it themselves. We can venture that a teacher who has personal experience of the reflective process is in better conditions to educate reflective students.

\section{The relevance of the reflective teacher}

After underlining the relation of reflection to professionalization, it is worth examining how reflection is connected to teachers' professional development. Cardeñoso, Azcárate and Flores (2001) assert that the explosion of industrial society in the 70s goes together with a concept that pertains to different fields, the notion of professionalization. In the educational field, this notion takes into account the teachers' role as helpmate, involving not only ethical aims through their human qualities, but also attending to people's needs. This means that teachers must become critical professionals continuously changing their perspective during the educational process, which is why they have to undertake a process of consistent professional development throughout their careers, involving different roles at different times.

Professional development is a personal issue, but it is influenced by external agents as well as internal processes, such as teacher training and the process of refection. There are social needs that lead teachers (and educational systems) to look at professional development as a process that must evolve and in which teacher training and the reflection process must be central to course design. During initial teacher training, teachers usually begin by adopting a descriptive position, which then gradually develops into a critical position with regard to their teaching practice and work context. During this process of growth, characterised by a gradual change possibly marked by gestalt moments, the teacher gradually gain prominence (Ponte, and Chapman 2008). In this way, in order to move forward in their professional development, teachers have to understand their practice as a process involving problematic situations that make them constantly revise their own performance, so that personal development depends very much on their personal circumstances and background. Teachers are the main agents of a process that begins in initial teacher training and it develops from there, taking into account personal events as influential factors in the consolidation of their professional identity. This constant process of revision is what shapes the teacher's professional identity as a reflective practitioner. Let us now consider "the role of teacher's reflection on their practice as a fundamental element for their development to occur" (Climent, 2005, 3), where his or her personal experiences are part of this evolution at all times. 
From the perspective of teacher change, Keazer (2014) considers the six phases proposed by Shaw and Jakubowski (1991) as a lens through which teachers make sense of the experiences that bring about change. These six phases describe the process the teacher undergoes in order to achieve an autonomous change, responding to the teacher's own objectives. In the final phase the teacher achieves continuous reflection of their practice. For Keazer (2014), professional development consists in the successful transition from one phase to another of this complex process of change, for which collaboration among colleagues is essential.

Given the importance of reflection, there is a strong case for it to be considered a fundamental element in training courses. Indeed, one means of ensuring that professional development programmes achieve high impact is to endeavour that "teachers actively reflect on their own practice by comparing it with the corresponding professional standards" (Marcelo and Vaillant, 2013, 115). Reflection is highlighted in different teacher training programmes around the world, and it contributes greatly to the creation of mental habits that stimulate continuous professional growth in practitioners as they progress in their profession (Mason, Klein, 2013). All of which suggests that the notion of a reflective teacher is current, trending and rightly so.

So far we have identified various motives and institutional decisions (emerging from the curriculum, for instance) that lead to the teacher becoming a reflective practitioner. We have also established the need to consider teachers as agents of reflection on their own practice, from the point of view of their professional development. It is a view consistent with that of various researchers, as will be seen below. Nor is it as recent an innovation as it might appear, and indeed its scope has influenced several fields.

From the perspective of general education, Zeichner (1993) reiterates the importance of having teachers as reflective professionals, asserting that,

the concept of the school teacher as a reflective professional recognises the mastery that good teachers' practice embodies. From the point of view of the specific teacher, it means that the process of understanding and perfecting their own teaching practice must start with reflection about their own experience (p.45).

Moreover, Van Manen (1995) raises questions about the meaning and the location of what he calls practical reflection in teaching, and about the relationship between knowledge and action in teaching.

Analysing the role that practical reflection plays in the process of teaching training in terms of its coverage in the literature, we can conclude that studies into reflection are increasing, and the topic now has a firmly established place within the field of general education (Korthagen and Wubbels, 1991). Thus, for instance, by the end of the $20^{\text {th }}$ century in the United Kingdom, Jaworski (1993) adjudged reflection on professional practice one of the key areas of her own research into mathematics teaching, asserting that it is one of the concepts associated with the professional life of every teacher. When describing the stages of the teacher's professional development - acquiring classroom management skills, expanding one's repertoire of teaching activities, gaining deep and diverse knowledge of the curriculum - the culminating stage is that of teacher reflection. In the Netherlands, Korthagen (1985) states that promoting reflection is an important objective in teacher education programmes, being an important means to professional development (Korthagen and Verkuyl, 1987). When reporting these authors' opinions about reflection in teaching training and the research into this area, the interest the topic has generated in current research should be noted.

Viseu (2008), examining initial teaching training, mentions that in general, programmes demand future teachers not to restrict themselves to being technicians or simply knowledge transmitters; rather they should be able to identify problematic situations in their practice and come up with appropriate solutions. Whatever the process is, teacher training is not the result of the accumulation of knowledge or techniques, but the outgrowth of interconnecting theory and practice through critical reflection on practice and the subsequent (re)construction of professional identity. Ribeiro (2010) notes that professional development is addressed in several research studies into mathematics education, some of which are focused on studying the different aspects that influence teachers' professional life (like teachers' beliefs and knowledge, among others), and adds teachers' reflection about their practice. The author points out that teachers' professional knowledge incorporates academic contributions that come from experience and reflection about teaching practice. In this way, reflection becomes ever more influential in the professional development of the teacher as the mediator of new knowledge.

It is thus, for example, that teaching reflection is considered by several contributors to the International handbook of mathematics teacher education (Tirosh and Wood 2008). For example, Schoenfeld and Kilpatrick (2008) introduce and develop a group of competencies that teachers must have 
in order to teach mathematics, which includes teachers' systematic reflection about practice. Empson and Jacobs (2008) introduce three recommendations for working with teachers, the third being teachers' reflection about their experience.

From all this we conclude that the concept of the reflective teacher is relevant to current concerns and is gaining adherents, and for good reason. We can add that it is not as new as it seems and is pertinent to various educational fields. In order to characterise what it is understood by the reflective teacher, we need move on to discuss what reflection is.

\section{What does it mean to be a reflective teacher?}

The most widespread notion of reflective teacher at present combines the humanist conception introduced by Dewey (1910) with the epistemology of practice added by Schön (Flores, 2007). It is true that these two authors' stance does not begin in education, but their works have enjoyed a strong influence on education. This has been especially so in terms of the connection between reflection and action, as required by teachers in their practice. In this respect, the notions of reflection-in-action and reflection-onaction have been especially influential. Reflection-in-action occurs when a moment of uncertainty arises which the teacher must deal with (a surprise moment as stated by Schön, 1983). It is a quick reflection conditioned by the presence and persistence of the problem itself, as the teacher strives to employ knowledge in action, combining practice and reflection. Reflection-in-action is carried out in the action itself, in the present moment. The teacher's thinking action serves to reorganise what we do as we perform. When the teacher has carried out some action, reflection-on-action comes up, which is a deep and long-lasting reflection process that leads the professional to reconsider solutions and seek different options, taking into account subsequent practice. We reflect on action when we pick up our thought about what we have done, so as to describe how our knowledge in action can contribute to an unexpected result. This can be schematised by Figure 1 .

Fig. 1 Reflection in practice according to Schön (1983)

From Dewey through to Schön, there has been a call to enhance teachers' practice through the development of habits of reflection, which can be called upon at any one of the three points identified by Schön. At these three points a new construct is present: professional knowledge, which is why we will continue defining the relationship between the teacher's reflections with teacher professional knowledge.

The study of teachers' professional knowledge has a decisive point with Shulman's ideas, who initiates the study of teachers' thinking. Shulman (1981) defines and identifies the pedagogical content knowledge to teach, studying what it consists of and how it develops. His stance makes us observe teachers as responsible professionals who have to position themselves with respect to professional knowledge in a reflective way, searching for items that help them fulfil their professional responsibilities without being restricted to apply techniques derived from theories, many of which they do not agree with or understand.

Reflection on personal experience fosters in teachers a process of understanding and perfecting their own teaching practice, characteristic of teachers as reflective professionals (Zeichner, 1993), thus recognising the wealth of knowledge derived from teaching practice. We then support the importance of the creation of reflection habits in professional development from the beginning of the teacher's practice, and extended along their life (Zeichner, 1993). This, consequently, means a change in paradigm that affects initial education as much as in-service training, which leads teachers to understand their practice. Climent's (2005) position on the notion of professional development is stated thus:

the starting point for professional development is gaining an understanding of one's practice. This development can be seen in the slowly developing awareness of the complexity attaching to practice and to the students' learning. It can also be seen in the teacher's analysis of their practice and their response, gradually incorporating more elements and gradually demonstrating better capacity to adapt to the learning of specific students. In our view it is a process of continuous development as a professional, both reflective and critical of their own practice (p. 119). 
This leads us to find strategies that favour reflective practice in teachers. Smyth (1991) places reflection as the central axis in teaching training, but he also analyses some obstacles to putting into practice the idea of critical reflection in teacher training and among teacher trainers. He claims that, in order to generate reflection, teachers must distance themselves from their practice, a notion shared by Jaworski (1993). In the sphere of mathematics education, the Comenius ${ }^{4}$ programme, a European initiative combining theory and practice in the classroom, promoted the idea of reflective learning ${ }^{5}$, considered as an interplay of "action" and "reflection". The key features of this approach to teacher training, based on a sociocultural perspective of human learning, are interaction with others and oneself, reflection and contrast in order to jointly construct and reconstruct knowledge (Alsina, Planas, and Calabuig, 2009), a process which Korthagen (2010) calls a "realistic approach" as it filters knowledge through the teacher's practical experience.

In this context, knowledge appears by means of a learning path through experiences. Korthagen defines "learning through experience" as developing knowledge, attitudes and skills with respect to oneself and the environment through one's own observation or systematic reflection under appropriate supervision (Esteve, Melief, and Alsina, 2010). These ideas are related to the notion of learning in practice as addressed by Jaworski (2006).

Continuing with the construction of the concept of reflection, Korthagen and Verkuyl (1987) review the literature concerning the concept, and offer the following description.

a person reflects when he is looking back on his experiences and/or knowledge and is engaged in establishing for himself a new structure or in assessing those experiences and/or knowledge (p. 4).

Fig. 2 Caricature of the reflective teacher: "I'll explain to you right now."

Korthagen takes up and develops the notion reflective thought set out by Dewey (1910), stressing the practical nature of the work of the teacher. This aspect is equally highlighted by Schön (1983), for whom reflection is triggered by a problem encountered in the teacher's practice, to the effect that the teacher is thrown into a state of surprise which can be resolved only through a process of revision of beliefs, and recognition of new alternatives. This connection between theory and practice is a key feature of what Korthagen (2010) calls a "realistic approach".

Korthagen's approach is consistent with Cooney's ideas (2001), for whom the notion of reflective professionals - that is, teachers capable of adapting their practice to circumstances - is central. Cooney advocates giving teachers the opportunity to take part in reflective thought, which for her implies something more than just looking behind.

Exploring teacher training and practice with the intention of putting into operation the notion of reflective professional practitioner, Flores (1997, 1998a, 1998b, 1998c) suggests that the following four dispositions and habits are essential (Flores, 2007, 145-146):

(1) Noticing circumstances which require personal action from the teacher.

(2) Distancing themselves from their practice in order to analyse the elements of the situations.

(3) Identifying and eliminating elements which distort the way the teacher sees these situations, including those coming from their own implicit beliefs or schemata.

(4) Seeking alternative sources in order to find new ways of interpreting the situations and responding to them.

Reflection offers teachers a means of restructuring their practice based on clear principles, and furthering their professional development. Schön (1983) underlines various features of the reflective practitioner, including the tendency to regard practice as something that regularly throws up challenges, a disposition to disengage from the immediate circumstances of a situation, and a habit of thought regarding how best to respond to such situations.

Given the importance of reflection to our work, we have carried out various studies into the reflective teacher (Ramos-Rodríguez, 2011, 2014), in particular focussing on analysing teachers'

${ }^{4}$ Comenius Project 2.1.: "Learning in and through practice: professionalization of future European teachers by reflective learning ", funded by the European Union (106150-CP-1-2002-1-NL). Duration: three years (2003-2005).

\footnotetext{
${ }^{5}$ Reflective learning originates in Plato and Aristotle (who promoted dialogue as key element of reflection and critical thinking), and was taken up by Rousseau and Dewey (the highest representatives of learning by experience), to arrive at modern interpretations.
} 
reflection in teacher training programmes. Taking into account various contributions to the topic with a view to gaining a clearer idea of the term, we added several further elements that complete the characterisation of the teacher as a reflective professional. Specifically, we added the following dispositions and habits:

(5) Forcing themselves to surpass the boundaries of their comfort zone: the zone they are familiar with and where feel safe (Korthagen 2010).

(6) Thinking through the significance of their practice, showing awareness of the complexity of practice and learning, and giving sense to their professional practice (Climent, 2005).

(7) Adapting their practical activity to the circumstances they find themselves in, such as taking into account the particularity of their situation, the individuality of their students, etc. (Cooney, 2001).

These seven essential features emphasise that the reflective teacher becomes aware of their responsibility to carry out their practice rationally, taking the time to look for solutions to the real problems that arise in their practice. To do so, they look back and revise or confirm their decisions at the planning and execution stages, and incorporate external perspectives (such as outside expertise and theoretical input) into their personal mode of operation.

By such means, the reflective teacher takes an active stance towards their teaching, grounding their practice and giving significance to their daily work. This process can be uncomfortable for people because it is often safer to cling to the things one is familiar with and to stay in one's comfort zone (Korthagen 2010). Finally, reflective teachers are also able to adapt themselves to the environment, looking for the possibilities that best direct their activity in the classroom in relation to the students, available resources, etc.

\section{Mathematics teacher exemplification}

In the course of our research we have noted certain observations in respect of the mathematics teachers' work, especially in the case of teachers with specific mathematics training, who are able to blend pedagogical knowledge with mathematical knowledge. We have seen that the way in which such teachers view challenging situations which occur in their lessons is often reflected in their capacity to disengage and identify the constraining factors that brought these problems to their notice. Thus we have noticed that there is some consistency in the type of issues that teachers perceive, tending to follow the sequence below:

A. Teachers identify professional problems affecting their practice, including situations that, according to them, constrain their work, such as deficiencies of the system (working conditions, lack of initiative from the authorities or parents, and so on), or student circumstances, such as lack of interest or motivation in studying mathematics, little or no knowledge of essential topics that should already have been assimilated.

B. They identify their lack of specific knowledge to teach as a professional problem. They consider their own training as lacking in basic teaching techniques such as classroom management. This tends to be especially true of mathematics specialists, whose expertise in content knowledge contrasts sharply with their narrow pedagogical content knowledge.

C. They gradually perceive that this pedagogical content knowledge, which influences their teaching performance in the classroom, is closely related to the way in which they view mathematical knowledge, and with the depth to which they manage this knowledge. Thus, they appreciate the interest in relating mathematics contents with their meaning - mathematical as well as phenomenological meaning (and with it pedagogical), appreciating what it means to students, what their function is in science, in teaching, etc.

For this reason we have come to appreciate that, in addition to the conditions for reflection above, teachers should be open to examining mathematics to whatever degree is necessary so as to be prepared for all eventualities. This also includes being willing to change their conceptions about mathematics, if needed, when situations in their practice require it. That is to say, we conclude our characterisation of the reflective mathematics teacher with two elements specific to the discipline:

8. Openness towards mathematics and a disposition to change their conceptions about it.

9. Being aware of the complexity of mathematical knowledge for teaching.

The former is related to the third habit noted by Flores (2007), but with a focus specific to the discipline. The latter is related to Climent's observation about the complexity of practice in relation to mathematics teaching. These two dispositions are intrinsic to the discipline, and concern the attitude of a mathematics teacher towards mathematical knowledge. In this case reflection extends to considering the 
very nature of mathematical knowledge, both the knowledge to be taught in school and the theoretical knowledge on which this is founded. Even so, we can talk of similar conditions in other disciplines, whereby the teachers' professional development could be organised in the same way considering the respective subject knowledge of each area. This means that, in general terms, irrespective of the profession, the role of reflection in professional development can be seen in relation to the knowledge required to work within the discipline in question.

The qualities demanded of a professional in order to practice in a given field are related in one way or another with the qualities of a reflective practitioner. Reflection is closely associated with professionalism, as this promotes the knowledge required to practise the profession and confers the necessary qualities to pursue the profession, irrespective of whether this is teaching or not.

In the following section, guided by the above conception of the reflective teacher, we give an account of a study into the reflections of novice teachers enrolled on a professional development course.

\section{Conditions governing the reflective mathematics teacher: a case study}

In this section, following a qualitative paradigm and a descriptive design, we discuss the nine conditions governing the reflective teacher, as evidenced in a professional development course designed to promote reflection among the participants. Ramos-Rodríguez (2014) gives an account of the course, with particular emphasis on how reflection led the teachers to reconsider their pedagogical content knowledge of mathematics in the area of school algebra.

Condition 1

At the beginning of the course, participants were encouraged to recall challenging classroom episodes that had demanded from them some kind of response (condition 1). One such episode outlined by one of the groups concerned mathematical modelling, specifically the students' difficulty in using mathematics to represent a situation described verbally. From this, it is possible to infer that the teachers considered algebra as a medium of communication between the student and mathematics, suggesting a conception of algebra as a language of mathematics (Caspi and Sfard, 2011; Drijvers and Hendrikus, 2003; Palarea, 1998). In contrast, it could equally be that the teachers locate specific aims of their teaching in their algebra lessons, such as the conversion of statements into algebraic expressions (equations), without any implication of their considering a wider and more functional idea of algebra.

The challenging episode (henceforth 'episode') identified by the participants from their practice took a pupil as the subject of study into a problem-solving task. This required them to represent a given problem with algebra, then solve the resulting equation to obtain the result. The participants' focus was on how the students learnt the process of representing real-life phenomena with algebra.

\section{Conditions 2 and 3}

Subsequently, the teachers shared their episode with the other participants and trainers, who guided them with questions such as 'What did I want?' 'How did I express it?' 'What were the chief elements making up the problem?' This had the effect of distancing the teachers from the experience so as to be able to analyse the elements of the episode (condition 2 of a reflective teacher), identify the beliefs on which it was based, note other related elements influencing the way these beliefs were perceived, including those derived from implicit schemes (condition 3)

In this phase of the course the teachers talked about the difficulties their students had in understanding what they were required to do. In this instance, the task involved using algebra to solve scenarios which they had previously tackled through arithmetic, and it was this that gave rise to their difficulties. In the course of their discussion of the episode, the teachers identified an aspect relating to teaching (what to do to make the task comprehensible), and three aspects relating to the task of using algebra to model the scenario: understanding the written description, constructing an appropriate mathematical model, and working through this to find the solution. Evaluating this situation with detachment, the teachers agreed that the episode was chiefly procedural in nature: 'How can I ensure that the students understand, interpret and solve a task using algebraic means?'

A subsequent session was given over to discussing the episode and the principles underlying it (Flores, 2000). Participants and trainers explored the implicit beliefs surrounding each group's episode, summarising these in sentences beginning, 'I think that the group believes that ...' and then discussing these summaries. It was agreed that the root cause of the episode above was best captured in the sentence, 'I think that the students do not understand what they read,' arguing that reading comprehension is a basic requisite for the students to solve a task.

In the following sessions the participants were encouraged to identify new elements from their episode in order to explore their understanding further, using prompt questions including 'What are the main elements making up the episode?' 'Where does it come from?' 'What level is it appropriate to?' and 'What mathematical content and procedures does it involve?' The teachers answered these questions and identified causes such as unfamiliarity with the cognitive demands of the task, as their students were more 
accustomed to memory-based tasks and had little experience of algebra. Another source of difficulty proposed was the lack of experience in using mathematical constructs to model real-life situations.

The teachers reached the conclusion that the task of 'translating' a written description of a scenario into an algebraic representation demands specific algebraic reasoning. They agreed that it was a non-trivial process, containing several elements which made it complex, as demonstrated when they considered the complexity of the mathematics involved in the task. At the same time they showed their experience and curricular knowledge in locating the task in the $7^{\text {th }}$ year of elementary education (around the age of 12). When asked to give a precise statement of the episode, they reworded the original version ("Why can't the students give a mathematical model for a problem described in writing?") as "Why can't the students interpret a real-life problem and represent it mathematically?" This illustrates how the teachers were becoming more precise in their use of terminology - they substituted 'give a model' for the more precise 'represent', they provided the context, and they stated the necessary step prior to deciding on the mathematical model, that of interpreting the written description. In effect, this gives greater prominence to the mathematical modelling through the recognition of the parts which comprise it. Condition 4

According to the course programme, once the teachers had defined the issues surrounding their episodes, there should then have begun a phase of looking for further information which would support them in their exploration of these issues. This involved reading articles which they found for themselves as well as others provided by the trainers. By this means the teachers would meet the descriptor for condition 4 of the reflective teacher, "drawing on other sources to find alternative perspectives on situations, and responding to these."

Nevertheless, the teachers' search for literature on the topic proved fruitless and they claimed that no papers were to be found which dealt with the issues they had identified. This is highly suggestive of their inexperience in carrying out this kind of basic research task, as they seemed to expect to find titles which literally broached the issues in the words which they had chosen to frame them.

Consequently, the trainers gave the teachers a research paper on the issues that had been raised by their episode, written by Puig and Cerdán (1990) and entitled "The arithmetic and algebraic features of written problems'. During the subsequent discussion of the paper, the dialogue below (Table 1) occurred between one of the teachers and one of the trainers:

Table 1: Dialogue about the input paper

\begin{tabular}{ll}
\hline Suject & Unit of analysis \\
\hline Teacher 1 & $\begin{array}{l}\text { There's a section which we underlined, and which I wanted to mention, and it's the process } \\
\text { of translating, because we ... }\end{array}$ \\
Trainer & And that's what you [all] wanted (to look at). Which is why we chose that paper. \\
Teacher 2 & $\begin{array}{l}\text { But the thing is that we still haven't - I mean, not in the paper we saw before nor in this one } \\
\text { - we still haven't been able to find what the underlying problem [root cause of the episode] } \\
\text { is. I mean, why was that [the pupils' difficulty in translating]? And as we saw, what helped } \\
\text { most was the topic of how the problem [task] could be schematized so that it can be solved. }\end{array}$
\end{tabular}

Trainer That offering, in inverted commas, was a way of finding a solution, but it doesn't explain what caused the difficulties.

Teacher 1 That's true, because what we need to find out is what caused this problem [the episode]

Table 11: Dialogue about the supporting paper

This excerpt illustrates the teachers' willingness to find support for their observations from outside sources (thus fulfilling condition 4 of a reflective teacher), although they continue to lay the emphasis on finding the source of their students' problems and pay special attention to the point in the paper describing ways to reduce difficulties through the use of diagrams as an intermediate step towards obtaining algebraic representations. The exchange shows this teacher's resistance to viewing the episode, 
such as she had articulated it, from another perspective and to employ unfamiliar techniques such as those proposed in the paper.

Nevertheless, after further consideration of the paper, the teachers' response was positive, as summarised by the following contribution: "the study suits us as it focuses on demonstrating that the problem [episode] lies with the comprehension and interpretation of the problem [task] and not in the solution." Hence it can be seen that the teachers were disposed to focus on the key aspects of assimilating the written statement of the task and reformulating it in a representative mode, rather than focussing on manipulation of algebra to find a solution. This is the key element of the reflective process indicating a substantive change in the group's concerns about the episode, and from this point on they dedicated their efforts to finding strategies to help he students reformulate this kind of written statement of algebraic problems.

\title{
Condition 5 and 8
}

Various debates arose during the course of the training programme. One such discussion concerned the year group to which the episode above was most appropriate. The teachers agreed on the seventh year of primary school, on the grounds that previous to this, the pupils are required to solve equations without having to derive them from written descriptions, and where this might be required, they would solve them in their head (by trial and error) without resorting to algebraic representation. From this stemmed a debate about the kind of tasks requiring algebraic treatment, exploring the role that algebra should play in school mathematics. It was observed that algebra is most appropriate when a task is not easy to solve arithmetically and an algebraic approach renders the solution more accessible. This observation led the teachers to consider the importance of being able to reformulate written problems so as to be able to mathematically model them effectively. In Korthagen's words, they were attempting to 'force themselves to surpass the limits of their comfort zone: the zone that is familiar for them and where they feel safe' (Korthagen, 2010). In this respect they met condition 5 of a reflective teacher, as well as displaying an open attitude towards mathematics and a disposition to transform their conceptions about it (condition 8).

\section{Condition 6}

In one of the training sessions, one of the teachers underlined the impact that the course was having on her teaching. She noted how her classes had tended to be teacher-focussed, but that as a result of participating in the course and discussing this kind of issue, she had made an effort to disengage herself from this role and place an increased focus on the students. In tandem with this change, she found that her lesson planning had also undergone revision, in terms of both mode and depth. We would regard this process as illustrative of a growing awareness of the complexity of teaching, characteristic of condition 6 of the reflective teacher (Climent, 2005).

\section{Condition 7}

At various points in the course the trainers asked the teachers to reformulate the fundamental issue underlying their episode. At one such point, following a group discussion, the same teacher rearticulated her original formulation, "representing a written description in algebraic language, using different strategies" to "algebraically modelling written problems".

\section{Versión después de discusión: \\ "modelar algebraicamente problemas verbales"}

\author{
Figura 3. Problemática reformulada, P.V.5.
}

The new formulation is succinct, and tackles only some aspects of the issues underlying the episode, but taking into account the teacher's contributions to the group discussions and her written observations, we 
can recognise certain processes at work. The teacher returns to an explicitly cognitive formulation which centres on what the pupils are expected to learn. Further, there is an awareness of the teacher's role, in that each pupil is recognised as an individual who might follow one particular strategy or another, such that the teacher will need to run a plenary session to evaluate which contributions arrive at the desired algebraic expression of the problem. What this recognition entails is a change of attitude towards the role of the teacher, from one of merely procedural concerns, supplying strategies, to one which supports the pupil in tackling problems, and in this respect we can say it comes under the auspices of condition 7 of the reflective teacher 'to adapt his or her practical action to the conditions of the context, such as making a decision considering the particularity of the situation, of the students to it is directed, of the students' individuality, etc. (Cooney, 2001)."

\section{Condition 9}

This condition, "becoming aware of the complexity of mathematical knowledge for teaching" can be noted in the teachers' first attempts to explore the episode, somewhat generalised and explained in terms of external causes, in comparison with subsequent attempts, which focus on the question of reformulating the problem in mathematical terms, without neglecting the other stages of modelling the problem algebraically. They later developed an awareness of the need to consider what is understood by the modelling process, what aspects intervene in the reformulation of the written description, and what elements of algebra are brought into play, recognising that these elements need to be clearly understood to avoid a recurrence of this kind of episode. Finally, they reworded their summary of the episode into a form which supported the pupils in their efforts to transpose the problem from the verbal to the mathematical plane, without losing sight of the fact that they were covering part of a more complete process. This is demonstrated in the rewording, which shows how they begin to pay more attention to the conceptual aspects of the modelling process. In this process they incorporate more algebraic elements, but without giving undue attention to the equations themselves, rather they recognise that the transposition of the problem can equally affect equations with more than one unknown.

Teacher change can be perceived in all these aspects (Keazer, 2014), with reflective practice as the ultimate stage in the process. The teachers' approach to teaching algebra developed in response to their own learning, by which they gained a new perspective on their practice.

\section{Conclusion}

In this paper, we have explored the definition of teachers as reflective practitioners, in the recognition that the domain of their reflection encompasses their professional responsibility to its fullest extent. Their willingness to engage with professional knowledge must go beyond identifying areas of deficiency, such as the technological knowledge for teaching that some authors call for (Contreras 2011). Teachers need to take advantage of tools which reveal the deeper concerns underlying their practice, such as the pedagogical content knowledge for mathematics identified by Shulman (1986), and greatly studied since. 


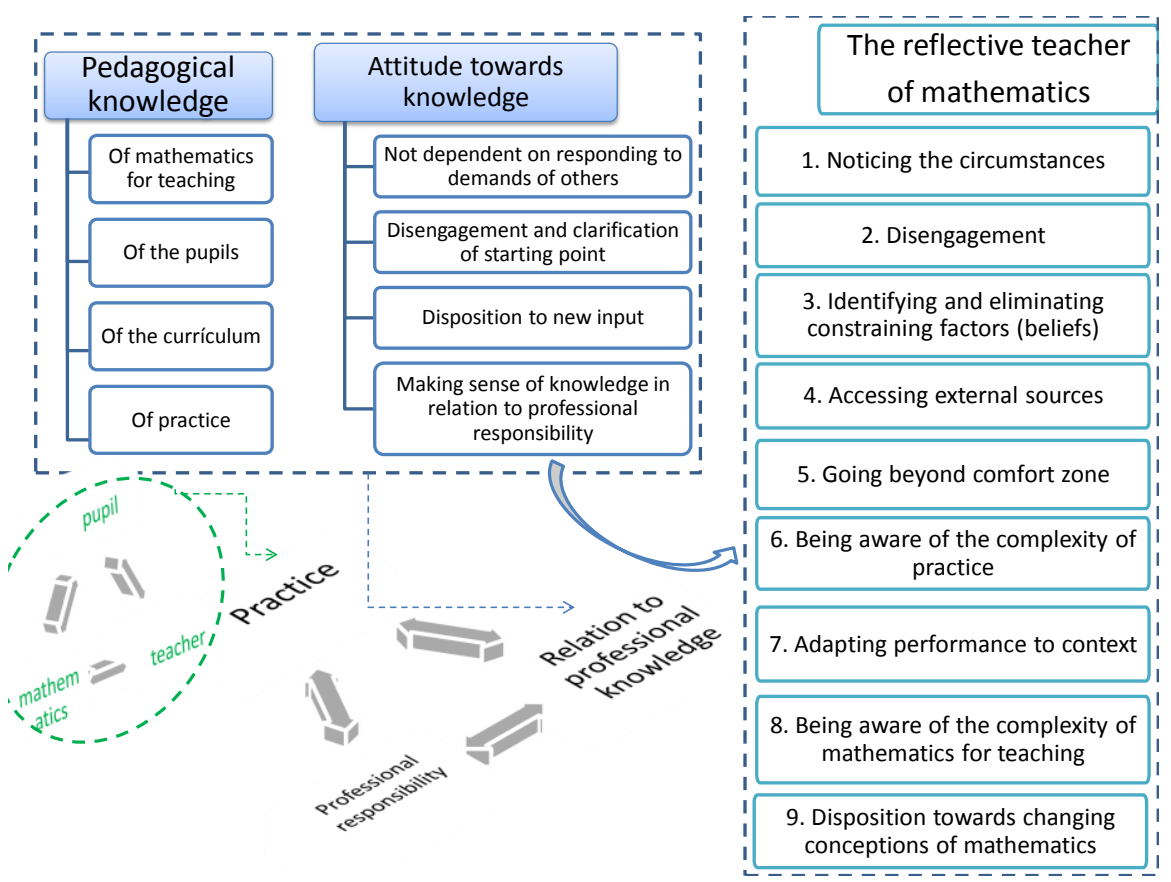

\section{Figure 3. Reflection and practice, professional responsibility and pedagogical knowledge}

The above discussion allows us to provide a detailed definition of the teacher as reflective practitioner, aware of their social responsibility. Using this term more accurately, avoiding ambiguities that may arise, helps to clarify this term, and at the same allow different educational agents (such as school teachers, teacher trainers or researchers) to have a clear and grounded view of what a reflective teacher is, and accordingly interpret its meaning, critique it, or adopt it, in the course of their practice, teaching training, or other professional demands on the teacher.

To this end, we employed this characterisation to study the reflection of mathematics teachers participating in a training course designed to promote this reflection (see Ramos-Rodríguez, 2014). This article describes the process which two of the participating teachers undergo, underlining the role of reflection in leading the teachers to reconsider their pedagogical content knowledge of mathematics, in our case, school algebra. As with other topics, reflection cannot be restricted to looking for new strategies to teach algebra, it must lead the teacher to examine what is understood by algebra, how it differs from arithmetic, what possible meanings symbols can take in algebra, as requirements to understand their professional responsibilities as algebra teachers.

\section{References}

Cardeñoso, J. M., Flores, P., \& Azcárate, P. (2001). El desarrollo profesional de los profesores de matemáticas como campo de investigación en educación matemática. En P. Gómez \& L. Rico (Eds.), Iniciación a la investigación en didáctica de la matemática. Homenaje al profesor Mauricio Castro (pp. 233-244). Granada: Publicaciones de la Universidad de Granada.

Clarke, D. (2008). The mathematics teacher as curriculum maker: Developing knowledge for enacting curriculum. En P. Sullivan \& T. Wood (Eds.), Knowledge and beliefs in mathematics teaching and teaching development: The international handbook of mathematics teacher education (Vol. 1, pp. 133-152). Rotterdan: Sense.

Climent, N. (2005). El desarrollo profesional del maestro de Primaria respecto de la enseñanza de la matemática: un estudio de caso. Tesis doctoral. Universidad de Huelva. España.

Contreras, J. (2011). La autonomía del profesorado. Madrid, Morata.

Cooney, T. J. (2001). Considering the paradoxes, perils, and purposes of conceptualizing teacher development. En F.-L. Lin \& T, J. Cooney (Eds.), Making sense of mathematics teacher education (pp. 9-31). Dordrecht: Kluwer.

Dewey, J. D. (1910). How we think. Boston, MA: D.C. Heath. 
Dewey, J. D. (1959). Como pensamos. Como se relaciona o pensamento reflexivo como processo educativo: uma reexposição. São Pau lo: Nacional.

Empson, S. \& Jacobs, V. (2008).Learning to listen to children's mathematics. En D. Tirosh \& T. Wood (Eds.), Tools and processes in mathematics teachers education: The international handbook of mathematics teacher education (Vol. 2, pp. 257-282). Rotterdan: Sense.

Esteve, O., Melief, K., \& Alsina A. (Eds.) (2010). Creando mi profesión: Una propuesta para el desarrollo profesional del profesorado. Barcelona: Octaedro.

Finlayson, A. (2016). Developing a reflective practice model for engineering leadership. Reflective Practice, 16(2), 1-13.

Flores, P. (1997). El profesor de matemáticas, un profesional reflexivo. En M.I. Berenguer et al. (Eds.), Investigación en el aula de matemáticas (pp. 13-27).Granada: THALES \& Departamento de Didáctica de la Matemática.

Flores, P. (1998a). Concepciones y creencias de los futuros profesores sobre matemáticas, su enseñanza y aprendizaje. Granada: Comares.

Flores, P. (1998b). Proyecto docente. Granada: Universidad de Granada.

Flores, P. (1998c). Formación inicial de profesores de matemáticas reflexivos. Uno: Revista de Didáctica de las Matemáticas, 17, 37-50.

Flores, P. (2000). Reflexión sobre cuestiones profesionales surgidas durante las prácticas de enseñanza. EMA, 5(2), 1-28.

Flores, P. (2007). Profesores de matemáticas reflexivos: Formación y cuestiones de investigación. PNA, 1(A), 139-159.

Fuentealba, R., \& Galáz, A. (2008). La reflexión como insumo para la mejora de las prácticas docentes en servicio: el caso de las redes locales. En J. Cornejo \& R. Fuentealba (Eds.), Prácticas reflexivas para la formación profesional docente: ¿qué las hace eficaces? (pp.141-168). Santiago: Ediciones Universidad Católica Silva Henríquez.

Goulet, M. H., Larue, C., \& Alderson, M. (2015). Reflective practice: A comparative dimensional analysis of the concept in nursing and education studies. Nursing forum. DOI: dx.doi.org/10.1111/nuf.12129.

Hatton, N., \& Smith, D. (1995). Facilitating reflection: Issues and research. Forum of Education, 50(1), 49-65.

Jaworski, B. (1993). The professional development of teachers: The potential of critical reflection. British Journal of In-service Education, 19, 37-42.

Jaworski, B. (2006). Theory and practice in mathematics teaching development: Critical inquiry as a mode of learning in teaching. Journal of Mathematics Teacher Education, 9(2), 187-211.

Keazer, L. (2014). Teachers' learning journeys toward reasoning and sense making. In J. J. Lo, K. R. Leatham \& L. Van Zoest (Eds.), Research trends in mathematics teacher education, research in mathematics education (pp. 155-180). Berlin: Springer.

Korthagen, F. (1985). Reflective teaching and preservice teacher education in the Netherlands. Journal of Teacher Education, 36(5), 11-15.

Korthagen, F. (2010). La práctica, la teoría y la persona en formación del profesorado. Revista Interuniversitaria de Formación del Profesorado, 68(24), 83-101.

Korthagen, F., Kessels, J., Koster, B., Lagerwerf, B., \& Wubbels, T. (2001). Linking practice and theory: The pedagogy of realistic teacher education. Mahwah, NJ: Lawrence Erlbaum.

Korthagen, F., \& Verkuyl, H. S. (1987). Supply and demand: Towards differentiation in teacher education, based on differences in learning orientations. Paper presented at the Annual Meeting of the American Educational Research Association, Washington. D.C.

Korthagen, F., \& Wubbels, T. (1995). Characteristics of reflective practitioners: Towards an operationalization of the concept of reflection. Teachers and Teaching: Theory and Practice, 1(1), 51-72. 
Little, M. O. (2015). The use of critical reflection in clinical practice and health profession education. Journal of the American Medical Directors Association, 16(3), 177-178.

Madrid, S. (2007). Profesorado, política educativa y género en Chile: Balance y propuestas. Santiago: Fundación Chile 21.

Marcelo, C., \& Vaillant, D. (2013). Desarrollo profesional docente ¿Cómo se aprende a enseñar? ( $3^{\mathrm{a}}$ Ed.). Barcelona: Narcea.

Mason, K., \& Klein, S. (2013). Land, sea and sky: Map making as reflection in pre-service teacher education. Reflective Practice: International and Multidisciplinary Perspectives, 14(2), 209-225.

Mewborn, D. S. (1999). Reflexive thinking among preservice elementary mathematics teachers. Journal For Research Mathematics Education, 30(3), 316-341.

Miranda, J. Ch. (2003). El pensamiento crítico en docentes de educación general básica en Chile: un estudio de impacto. Estudios Pedagógicos (versión on-line). No. 29. Consultado el 5 de diciembre del $2011 \quad$ en: http://www.scielo.cl/scielo.php?pid=S0718$07052003000100003 \&$ script=sci_arttext\&tlng=pt.

OCDE (2003). The PISA 2003 assessment framework: Mathematics, reading, science and problem solving knowledge and skills. Paris: OCDE.

Oliveira, I., \& Serrazina, L. (2002). A reflexão e o professor como investigador. In Associaçao de Professores de Matemática (Ed.), Reflectir e Investigar sobre a prática profissional (pp. 29-42). Lisboa: APM.

Ponte, J. P., \& Chapman, O. (2008). Preservice mathematics teachers' knowledge and development. En L. English (Ed.), Handbook of international research in mathematics education (pp. 225- 236). New York, NY: Routledge.

Ramos-Rodríguez, E. (2011). Reflexión de docentes sobre la enseñanza del álgebra en un programa formativo. Trabajo de fin de Máster, Departamento de Didáctica de las Matemáticas de la Universidad de Granada, España.

Ramos-Rodríguez, E. (2014). Reflexión docente sobre la enseñanza del álgebra en un curso de formación continua. Tesis doctoral: Universidad de Granada. Granada, España.

Ribeiro, C. (2010). El desarrollo profesional de dos maestras inmersas en un grupo de trabajo colaborativo, a partir de la modelización de sus clases de Matemáticas. Tesis Doctoral, Universidad de Huelva. Huelva, España.

Schöenfeld, A., \& Kilpatrick, J. (2008). Toward a theory of proficiency in teaching mathematics. In D. Tirosh \& T. Wood (Eds.), Tools and processes in mathematics teachers education: The international handbook of mathematics teacher education (Vol. 2, pp. 321-354). Rotterdan: Sense.

Schön, D. (1983). The Reflective Practitioner: How professionals think in action. London: Temple Smith.

Schön, D. (1987). Educating the reflective practitioner. San Francisco, CA: Jossey-Bass.

Shaw, K. L.; \& Jakubowski, E.H. (1991). Teachers changing for changing times. Focus on Learning Problems in Mathematics, 13(4), 13-20.

Smyth, J. (1989). Developing and sustaining critical reflection in teacher education. Journal of Teacher Education, 2(40), 2-14.

Smyth, J. (1991). Una pedagogía crítica de la práctica en el aula. Revista de Educación, 294, 275-300.

Shulman, L. S. (1986). Those who understand: Knowledge growth in teaching. Educational Researcher, 15(2), 4-14.

Tirosh, D., \& Wood, T. (Eds.). Tools and processes in mathematics teachers education: The international handbook of mathematics teacher education. Rotterdan: Sense.

Van Manen, M. (1995). On the epistemology of reflective practice. Teachers and Teaching: Theory and Practice, 1(1), 33-50.

Viseu, F. A. V. (2008). A formação do professor de matemática, apoiada por um dispositivo de interação virtual no estágio pedagógico. Tese de doutoramento, Universidade de Lisboa.

Zeichner, K. (1993). El maestro como profesional reflexivo. Cuadernos de Pedagogía, 220, 44-49. 